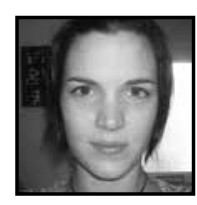

\title{
"School Readiness": The Struggle for Complexity
}

\author{
Katherine Evans, University of Exeter
}

\section{ABSTRACT}

This article highlights the challenge of engaging critically with dominant discourses of "readiness" in early childhood education. Drawing on the current context of early childhood education in England, this paper argues that dominant discourses of "readiness" are reliant on an underlying logic of mechanistic causality that acts to reduce complexity and marginalize difference and diversity. Calling for a radical reconceptualization of "readiness," experiences from practice are weaved throughout this critical discussion, highlighting the impact of dominant discourses of "readiness" in situated practice and the challenges that can be faced by engaging critically with this discourse.

\section{Introduction}

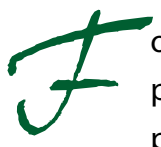

or many years debates concerning early childhood education have had a particular interest in notions of "readiness." The "Starting Strong" reports, published by the Organisation for Economic Co-operation and Development (OECD, 2001, 2006, 2012), identified contrasting international trends in the conceptualization of "readiness" within educational debates, influenced broadly by either a "social pedagogy tradition" or a "pre-primary" approach to early education. Social pedagogy approaches were found most commonly within Nordic and Central European countries, whereas pre-primary approaches were identified within countries such as Australia, Canada, France, the Netherlands, the United Kingdom, and the United States (OECD, 2006). Pre-primary approaches were broadly characterized by a focus on the "knowledge and skills useful for school, viz., literacy, math and scientific thinking" (OECD, 2006, p. 61). Also recognized was a tendency for this approach to focus on a standardsbased model of education, referencing particular child outcomes as a measure of what 
children should know and be able to do as a result of their participation in early childhood education.

Moss $(2012,2013)$ has linked pre-primary approaches with a dominant discourse of "readiness" that conceptualizes early childhood education and care as a preparatory phase, readying children for the specific demands of compulsory education. Moss identifies England as an active example of this dominant "readiness" discourse, highlighting the prominence of "readiness" within education policy and decisionmaking. He cautions that the status of this dominant discourse is problematic, being underpinned by conservative views of the child, education, learning, and knowledge, that are taken for granted within the context of compulsory school education and pushed down into early childhood education policy and practice. Within this article it is argued that dominant conceptualizations of "readiness" are detrimental for some children, acting to systematically reduce complexity in the way that their learning and development is understood and valued within early childhood settings. Linking this critique to Deleuzian notions of "becoming" (Stagoll, 2005a) this article proposes an alternative way of thinking about "readiness" in early childhood education, that works against the systematic complexity reduction (Lenz Taguchi, 2010; Gustafson, 2010) of currently dominant discourses, and strives for understandings of "readiness" that recognize difference and diversity as positive aspects of educational communities.

The first part of this paper provides an overview of the English policy context for early childhood education, leading to a discussion of the conceptualization of "readiness" within this political policy context. The second part engages with dominant notions of "readiness" as mechanisms of complexity reduction and discusses the potential of reconceptualizing "readiness" as a concept of "becoming." This critical discussion and reconceptualization is emergent from the early phases of my doctoral work which focuses on challenging and reconceptualizing dominant discourses of "readiness" in early childhood education in England. Reflections from my own professional practice as an early childhood teacher are woven into the text, in the hope that they may resonate with others, providing a stimulus for the critical consideration of concepts and practices of "readiness" and of the challenges faced in early childhood education.

This paper concludes by highlighting the need for research and critical thinking that engages with "readiness" at both a conceptual level, challenging the theoretical ground on which dominant understandings are based, and also exploring the possibilities for alternative understandings of "readiness" which might have an impact on policy and practice and on the day-to-day experiences of early childhood communities. 


\section{The English Policy Context}

Early childhood education in England has recently undergone a process of review and transformation. The current iteration of policy guidance, the Statutory Framework for the Early Years Foundation Stage (EYFS) (DfE, 2012), encompasses official standards for learning, development, and care for children from birth to the age of five. The EYFS encompasses early childhood education throughout preschool and the first (Reception) year of primary school. As a statutory framework, the EYFS "sets the standards that all early years providers must meet to ensure that children learn and develop well and are kept healthy and safe" (p. 2). The position accorded to "readiness" as an outcome of the EYFS is explicit, stating that, "It [the EYFS] promotes teaching and learning to ensure children's 'school readiness' and gives children the broad range of knowledge and skills that provide the right foundation for good future progress through school and life" (p. 2). Crucially, the statutory framework specifies that planning, provision, and assessment must be built around seven particular areas of learning and development and that all children must be guided towards the achievement of 17 "Early Learning Goals" (ELGs) - statements that detail the knowledge, skills, and understanding that children should have acquired by the end of the EYFS.

In addition, a series of non-statutory materials (Early Education, 2012; DfE, 2013) are available to support the ongoing formative assessment of children's progress towards the ELGs in all seven areas of Learning and Development. These materials are intended to be used "throughout the early years as a guide to making best-fit judgments about whether a child is showing typical development for their age, may be at risk of delay or is ahead for their age" (DfE, 2013, p. 3). Each aspect of learning and development is broken down into a "typical range of development," denoted by a series of six overlapping age/stage bands leading to the ELG in each area. At the end of the EYFS each child's progress and "readiness" for the next stage of education is assessed against the ELGs as part of the statutory EYFS Profile (Standards and Testing Agency, 2013). This summative assessment judges whether children are considered to be meeting, exceeding, or not yet reaching expected levels of learning and development (DfE, 2012), and therefore whether they are considered "ready" for more formal learning in Key Stage 1. 


\section{Readiness in the EYFS}

Meisels (1999) highlights the complexity of characterizing "readiness," identifying four dominant conceptions: idealist/nativist; empiricist/environmental; social constructionist; and interactionist. Dominant within the EYFS are understandings based on idealist/nativist and empiricist/environmental conceptions. An idealist/nativist frame understands "readiness" as a phenomenon that occurs within the child, dependent on inherent, maturational processes. With strong links to concepts of "readiness for learning" (Kagan, 2007), "readiness" in this context relates to developmental progression within which children are considered "ready" to undertake specific learning once they have acquired particular developmental capacities. This focus on maturational development is evident in the construction of pedagogical progression advocated by the EYFS, which states that, "As children grow older, and as their development allows, it is expected that the balance will gradually shift towards more activities led by adults, to help children prepare for more formal learning, ready for Year 1" (DfE, 2012, p. 6). This expected progression assumes that development precedes and determines learning and that a child's level of maturational development determines what they are "ready" to learn and how they are "ready" to learn it. This maturational concept of "readiness" is also evident within the structuring of the EYFS support materials and their use of norm-referenced developmental statements to suggest a "typical" trajectory towards the ELGs. It is expected that whilst children's developmental rates of progress will differ they will follow a more-or-less typical trajectory, deviation from which may be an indication of deficit in the child.

In contrast to this idealist/nativist frame there is evidence of "readiness" as an empiricist/environmental concept (Meisels, 1999). Within this frame, "readiness" is emphasized as an apparatus that provides children with the skills, knowledge, and experiences they are considered to need to be ready for formal schooling (Brown, 2010). This is evident within statements of purpose in relation to the EYFS framework including: that it "defines what providers must do (...) to promote the learning and development of all children in their care, and to ensure they are ready for school" (DfE, 2012, p. 4) [emphasis added]; and, in relation to the ELGs, that they "summarise the knowledge, skills and understanding that all young children should have gained by the end of the reception year" (p. 4). In contrast to the nativist focus on "readiness for learning" (Kagan, 2007; Whitebread and Bingham, 2011), this environmental model can be related to a concept of "readiness for school." Kagan (2007) identifies this as a more "finite" construct than that of the developmentally driven "readiness to learn." It can be considered a more "concrete" form of "readiness," focusing on external influences and observable 
evidence of learning and development. The desired end of this form of "readiness" is the acquisition of specific knowledge, skills, and experiences that are explicitly "taught" to children through interaction with their environment. The role of the adult in fostering this form of "readiness" is to "guide the development of children's capabilities" (DfE, 2012, p. 4) ... "through a mix of adult-led and child-initiated activity" (p. 6). Children's engagement with their social and physical environment is therefore expected to underpin the learning and development of specific key skills and capacities needed to become "ready for school."

The complexity of "readiness" within the EYFS means that these contrasting conceptions do not operate in isolation. They interact, contradict, and impact upon each other, contributing to understandings and interpretations of "readiness" in practice. These conceptions are also among a number of different understandings and interpretations of "readiness" in the context of early childhood education practice. It is argued here, however, that these are the most dominant contemporary influences on "readiness" as a policy discourse and therefore have particular significance for the way in which "readiness" currently is understood and enacted within mainstream early childhood settings, as the following reflection indicates.

\section{Reflection 1}

At the time I was the local nursery teacher and it was the beginning of the academic year. I was meeting with the local school to discuss their current intake of Reception children. I remember feeling frustrated as children were talked about as points on a scale, categorized into groups according to age/stage bands. Individual children's successes and challenges were discussed only in terms of the pre-determined skills, attributes, and goals detailed in the EYFS and specifically the Early Learning Goals. Particularly frustrating was the apparent lack of interest in the individuality of the children themselves. A colleague of mine, in response to concerns over a child's ability to sit still and concentrate for the duration of a teacher-led session, made reference to documentation from his time in nursery, showing him sustaining focus for periods of over one hour. The response was that this level of focus was only within activities he had chosen and developed himself, and he now needed to learn to behave appropriately in "classroom situations." Discussion continued in this vein and I felt that my practice as a nursery teacher was being called into question, being criticized for not drilling children in how to sit still and keep quiet, ready for school-based learning. I remember wondering where the space was for individual children's passions and creativity, for teaching strategies that focused on the complexity the children themselves brought to the school environment, as opposed to how they could be brought to conform to expected and predicted identities and characteristics. It seemed that the complexity and difference that 
children brought to the school environment was being silenced by the traditional practices and discourses of the school culture, being systematically suppressed and channelled along pathways that could only ever lead to a narrow and limited form of success, or else failure.

\section{A Political Rhetoric of "Readiness"}

The past few years in England have seen significant government concern over children's "readiness" to start compulsory schooling. This concern has been particularly evident within political discourse and decision-making emanating from speeches and government commissioned reports. In a speech made in 2011, the English Secretary of State for Education declared that, as a nation, "we need to make sure that children arrive in school ready to learn" (Gove, 2011). The apparently escalating political anxiety over children's "readiness for school" and the related concept of "readiness to learn," was clearly demonstrated through Gove's concern that, on starting school, "... a growing number of children cannot form letters or even hold a pencil. Many cannot sit still and listen. Many can scarcely communicate orally, let alone form a question" (Gove, 2011). Gove alludes here to a concern over the kind of "readiness for school" discourse described above, within which children are considered to be emerging out of the EYFS without the knowledge and skills considered necessary to participate successfully in a school environment. The outcome of this escalating political anxiety has been identified as leading to increasing intervention by government in early childhood education and care (Whitebread \& Bingham, 2011). Since 2010, the English government has commissioned a series of "evidence-based" reports focusing on the importance of the early years in preparing children to be successful in later life (Field, 2010; Allen, 2011; Tickell, 2011). In response to the Government's interpretation and use of the recommendations of these reports, there has been mounting tension among the English early childhood sector that an increasing focus on a specific notion of "readiness," as a normative developmental goal and the acquisition of particular knowledge and skills, is leading to children being measured against "a 'deficit model', a set of inappropriate, one-size-fits-all standards of 'readiness' for school" (Whitebread \& Bingham, 2011, p. 1).

These concerns are connected with what the $\operatorname{OECD}(2001,2006)$ and Moss (2012, 2013) describe as "schoolification." The 2001 OECD Starting Strong Report warned of "a risk of downward pressure from a school-based agenda to teach specific skills and knowledge in early years" (p. 41). The 2006 OECD Report built on this concern highlighting that the "readiness for school" discourse dominant in many countries was attractive as it held out "the promise to education ministries of children entering primary school already prepared to read and write, and being able to conform to normal classroom procedures" (p. 63). In England, this "school-based agenda" has been strongly focused 
on the raising of standards and outcomes for children at later points during their school careers, and this downward pressure has been critiqued as bringing inappropriate practice into early childhood education, subjecting children's formative experiences to a "conservative and impoverished form of education" (Moss, 2012, p. 15).

It is important to note, however, that whilst "schoolification" may have connotations of "taking over early childhood institutions in a colonising manner" (OECD, 2006, p. 62), this has not necessarily been the explicit intention of education ministries and teachers, who in many countries have been "strong advocates of learner-centred education and active learning methods" (p. 62). It is my contention in this paper however, that whether or not "schoolification" is an explicit intention of governments and policy makers, its effects are evident within current policy frameworks, and for some children, this is having a detrimental impact on their early childhood experiences.

\section{Reflection 2}

For some children starting school is a positive experience. For others, however, the transition is not so smooth. Toby (pseudonym) had not always had an easy time at nursery and relied heavily on the relationships he had built with key people. He had attended nursery full time for many years and routines and experiences had been adapted in order to provide an environment within which he could know success. His transition to school had been carefully planned with his new teacher, however I was anxious about how he would take to this new environment and to the increased structure and different expectations. Through discussions with his new class teacher I was acutely aware of her concern that it would be significantly more difficult to adapt the traditional routines and expectations of the school environment than it was in nursery. She was concerned over the much lower ratio of adults to children and worried that he would struggle with the culture of whole class participation and the increased proportion of time he would be expected to participate in adult-led activities, over which he would have little or no control. I remember talking to his class teacher after Toby had been in school for a few months. She emotionally told me that he was now attending school part time, that it had been decided that he was not "ready" for full-time attendance. She told me about her feeling of failure that she could not provide an environment that supported him, but that the expectations on her, on how she would perform as a teacher, would not allow for her to make the adjustments she felt she needed to. She told me of the pressure to deliver whole class literacy and numeracy sessions and the expectation that all children participate. She told me of her struggle to support this child under the very great expectations of the school culture and shared her concern that she could not see, in this environment, how this child could ever be successful. At four years old, in this academic world, he was already a failure! 


\section{Mechanisms of Complexity Reduction}

Among the most detrimental effects of this "schoolified" discourse of "readiness" is its operation within early childhood contexts as a mechanism of complexity reduction. Lenz Taguchi (2010) suggests that policy makers tend to look for general structures and one-dimensional standards for practices that would seem to provide consistent and equal quality for all by treating and evaluating everyone by the same universal, comparable, and centralized standards. Biesta (2010) states that one of the most prevalent ways in which complexity is reduced within educational contexts is through assessment practices that decide which outcomes of learning count. In the context of the EYFS, this complexity reduction can be linked with a dominant discourse of "readiness." Understanding the ELGs as summarizing "the knowledge, skills and understanding that all young children should have gained by the end of the Reception Year" (DfE, 2012, p. 4), it can be interpreted that these goals act to validate the learning and development trajectories that are officially considered to be important in terms of children's "readiness" for Year 1. This validation becomes problematic since by selecting certain desirable characteristics of "readiness" in relation to learning and development, the ELGs, by definition, act to invalidate and exclude other characteristics that may be considered, in this policy context, irrelevant or less desirable in terms of "readiness" in a school environment.

The EYFS is a particularly interesting example of the type of complexity reduction discussed by Lenz Taguchi (2010) and Biesta (2010). Among its overarching principles, the EYFS states a belief that "every child is a unique child, who is constantly learning" (DfE, 2012, p. 3) [emphasis original]. As Biesta (2010) identifies however, if it is granted that learning is a ubiquitous phenomenon in which children are continuously engaged, then the use of assessment processes that make reference to specific goals and outcomes can be seen as a very specific way to channel or tame that learning. This notion of "taming" is also explored by Olsson (2009) who states that a lot of effort is put into the "taming" of children's subjectivities through processes of "predicting, controlling, supervising and evaluating according to predetermined standards" (p. 6). These act to fix representations of "readiness" and do not allow room for movement or flexibility in terms how "readiness" is understood in the context of early childhood education. "Readiness" is conceptualized as part of a linear hierarchy within which children move progressively toward a threshold of "readiness" which, once passed, leads to a higher level of learning and development. The kind of logic that underpins this hierarchical notion of "readiness" can be understood through the metaphor of the tree, assuming a mechanistically linear structure within which learning and development work through fixed and deterministic relationships of cause and effect. Within this aborescent schema 
(Stagoll, 2005b) the ordering of progression is strictly hierarchical, with each element, or developmental outcome, fixed in its final position according to a superior concept (Stagoll, 2005b) or understanding of "readiness." As the logic of this schema does not permit movement that cuts across or diverges from the hierarchy of learning and development, it acts to reduce the number of officially valued outcomes and trajectories to those represented within statutory assessment mechanisms. Space for outcomes that may be different, unexpected, and unpredictable risk becoming squeezed out of such a reductionist framework and the conservative educational climate that produced it.

This reduction of complexity is recognized by Moss (2013) who claims that current systems of early childhood education in England are aligned with "a dominant narrative of normativity and performativity in which the purpose of education is conformity to predetermined performance criteria" (p. 5). It is argued here that such systems act to foster a hierarchical concept of "readiness" that assumes, not only that early childhood must serve the needs of subsequent stages of education, but also that practices and pedagogies are only of value in relation to how "effectively" they achieve specific goals and outcomes for all children. Ball (2003) suggests that central to the functioning of this type of performative regime is the translation of complex social processes and events into simple figures and categories of judgment. He also suggests that the operation of performative technologies, such as curriculum frameworks and assessment procedures, are instrumental in reducing complexity within educational environments. He states that complex organizations, such as schools, are multifaceted and diverse and that within a performative regime it is likely that the choice of what is to be privileged and cultivated will be informed and driven by priorities and constraints set by the policy environment. Within an environment that claims to believe that "every child deserves the best possible start in life and the support that enables them to fulfil their potential" (DfE, 2012, p. 2), it is ironic that this potential is measured according to such fixed goals and outcomes, that effectively position some children as falling perpetually short of where their potential for learning and development is considered to be. Lenz Taguchi (2010) alludes to this paradoxical trend in early childhood education, stating that the more the complexity of early childhood settings increases, through a "push for increased inclusion of children and families with diverse ethnic, racial, cultural, social and economic backgrounds" (p. 14), the greater the desire seems to be for processes of reduction and increased control that risk shutting out the very inclusion, equality and social justice they aim to achieve. She suggests that such a hierarchical model of education will always begin by defining the outcomes upon which educational practice is to be built, starting with what is to be achieved and assessed. Based on such understandings, the effectiveness of pedagogical practices can only be understood as corresponding to the outputs they generate and their accordance with prescribed standards and 
outcomes. The logic of this system therefore rests upon an ontological certainty about the value of particular aspects of knowledge and modes of expression and their position within a fixed hierarchy of knowledge.

Crucially, it is not just the assessment act itself that reduces complexity in this context. The recursive process of "planning, observation and assessment" that is recommended within the EYFS support materials (Early Education, 2012) embeds the effects of complexity reduction throughout the system as a whole. Biesta (2010) describes this effect as the "anticipation of assessment" (p. 9), which in relation to the EYFS means that early childhood educators, in the process of planning and evaluating their support of children's learning and development, will themselves "select certain actions and not others in anticipation of the intervention of assessment later on" (p. 9). Complexity is therefore not only reduced for the ways in which children's learning and development is understood and valued, but also for the experiences that are offered to children within early years learning environments.

\section{Mechanistic Causality}

As an early childhood teacher I have often experienced a struggle between meeting the professional demands of an outcome-driven and assessment-led curriculum, influenced by particular dominant discourses of "readiness," and finding space for the complexity of children's learning and development to emerge and be valued within a wider concept of "readiness" that is cognizant with such complexity. A significant contributory factor within this struggle has been the underlying logic that informs dominant, policy-based notions of "readiness." This logic can be referred to as a form of "mechanistic causality" that works according to an aborescent schema (Stagoll, 2005b), the effect of which is an education system that is considered to operate close to a state of equilibrium, within which trajectories between inputs and outputs are considered to work through stable and deterministic mechanisms (Biesta, 2010). Specific pedagogical inputs and early intervention strategies are seen as technical foci, the application of which should bring about specific learning and development outcomes for all children. The child, therefore, becomes the effect of such disciplinary mechanisms (Simons \& Olssen, 2010), with anomalies being explained by recourse to an idealist/nativist notion of developmental deficit within the child. This reductionist approach fosters a hierarchical understanding of the value of certain outcomes in relation to specific inputs. In relation to "readiness," those outcomes that align with the needs and demands of compulsory school education and that prepare children to be successful within a mainstream school environment are privileged, creating "calculable divisions in ability that order participation along these lines" (Gustafson, 2010, p. 96). 


\section{"Becoming-ready": reconceptualizing the logic of "readiness".}

Whilst certain conceptualizations of "readiness" may be dominant in the English early childhood education system, this does not mean that there are no alternative understandings. In challenging dominant notions of "readiness" in the EYFS, this paper argues that it is necessary to critique and reconceptualize the very foundations on which these dominant understandings are based. In contrast to the currently dominant notions of "readiness" described in this paper, I believe that the notion of "becoming" has the capacity to open up to new ways of thinking about, and engaging with, "readiness" in early childhood education. Specifically, this notion of "becoming" is inspired by Deleuze and Guattari (1987), who conceptualize "becoming" not as a fixed linear relation or correspondence between points, but as the flow of experimentation and change that occurs in the state of being in-between. A concept of "becoming-ready" therefore would shift the focus of "readiness" from the acquisition of specific learning and development goals, to the process of learning and development, to the "connections and micro-events" (Jackson, 2013) that occur through children's engagement with their world. Crucially, this concept of "becoming-ready" would value process in its own right, as the here and now, the complexity of the moment, rather than as merely a mediator for future development or as preparation for things to come (Olsson, 2009). Where a concept of "becoming-ready" departs radically from dominant notions of "readiness" is in its rejection of fixed goals and outcomes. Not only is the concept of a predetermined standard of "readiness" undesirable, it is incomprehensible within this framework of "becoming." As Jackson (2013) states, "Becoming is a constant, fluid process of changes, interactions and transformations" (p. 117) and as such, who or what a child is to "become" cannot be predicted in advance of the moment of "becoming." The concept of "readiness" as concretely represented within assessment and curriculum policy is unthinkable from this logic as it implies, not only that "readiness" can be fixed as a state of becoming, but also that until this fixed state is reached, the child is somehow incomplete. However, in rejecting the determination of fixed goals and end points, a concept of "becoming-ready" recognizes that children are constantly engaged in "processes of complex material unpickings and entangled situations" (Cole, 2011, p. 552). The child cannot be considered incomplete as there is no fixed outcome of "readiness" waiting in the future for them to aspire to. They are complete in each moment as they engage with their world, each moment becoming something else and being confronted with their "readiness" for situations as they arise over and over in the moment. As Sellers (2013) states, "becoming is not about becoming anything spe-

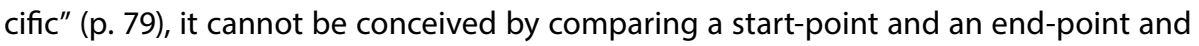
deducing the differences between them (Stagoll, 2005). A Deleuzian understanding of "becoming" does not aim towards the kind of teleological orientation of goals and outcomes that dominate early childhood education policy. Instead, it pushes beyond 
the known, beyond the predetermined destinations and end points to the unknown new (Marble, 2012). Of importance within this conceptualization of becoming is the movement and flow that occurs as children reach out to their unknown potential and connect with their world in the process of creating and solving problems. Olsson (2009) likens this kind of "becoming-in-the-moment" to the activity of a surfer, stating that: "The surfer surfs not to get ahead, to get somewhere, but for the moment. Surfing is about living the moment to the fullest capacity of one's body, and to stretch out beyond that" (p. 5). As the surfer takes on each new wave, they test their "readiness" to respond to the situation that presents itself. Their "readiness," as the child's, can be understood as being constructed in their creative responses to the problems and challenges the world presents and in their potential for acting and affecting as they "vibrate and resonate together with the world in the process of solving/constructing problems" (p. 5). Crucially, becoming-ready is never a concrete or finalized state as it happens continuously, over and over again in the complexity of daily life. The event of becoming-ready can never be predicted or prescribed in advance. As Sellers (2013) reminds us, for Deleuze and Guattari, becoming does not involve progression or regression culminating in specific ends, and as such, becoming-ready does not correspond to the successive acquisition of specific skills and attributes.

\section{Reflection 3}

I remember observing a teaching student leading a music activity with a group of children, all of whom were due to start school in the coming Autumn term. Part of this group was a young girl about whom the nursery team had raised concerns regarding her "readiness" to start school. I watched as the student teacher tried hard to involve her in the activity but the girl repeatedly wandered away from the small circle of other children, choosing other resources and spaces to be in at that moment. After a few attempts to bring her back to the group, the frustrated student gave up and left her, crouched beside a nearby table where she had found a small selection of play people. As the observation continued my attention was drawn repeatedly back to this child. She watched as the group sang and acted out counting songs and I could hear her humming the tunes, interspersed with lines from the songs. As the group mimed frogs jumping, one by one into a pool, she made her play people jump off the table one by one. It struck me that she was just as engaged with the content of the group activity as any of the children still in the circle; she had just chosen her own manner of participation. Reflecting on this episode now, sometime later and in the context of "readiness," I can see how my concerns over this child's "readiness" for school were deeply invested in normative notions of "readiness" as being linked to following adult direction and performing a particular type of participation. As a process of becoming-ready however, the complexity of this child's participation can be seen. Presented with a challenging situation 
she had developed her own strategy for successful participation. Each time she moved away from the group she remained within visual and auditory range, continuing to listen and respond to the group from the alternative spaces she had chosen. Presented with a problem, that of sitting with the group throughout this activity, she had constructed her own creative response: In that moment she had created the context for her own readiness to participate. Her "readiness" did not conform to the normative notion that dominated my thinking at the time, but nevertheless she acted effectively in the process of her own becoming-ready and in responding to the challenge that faced her.

\section{Conclusion}

Gustafson (2010) asks, "Where is the space for additional complexity" (p. 98) in contemporary education. In concluding, this article asks the same question of the early childhood field in England. In a regime dominated by discourses of "readiness" that privilege norms, goals, and outcomes, where is the space for those outcomes of early childhood education and those experiences of childhood that fall outside of these predetermined categories? Where is the space "for outcomes that are not predetermined, that are unexpected, that provoke surprise and wonder?" (Moss, 2013, p. 41).

In his critique of "the resistible rise of school readiness," Moss (2012, p. 355) advocates a reconceptualization of the relationship between early childhood and compulsory school education and, as a result, understandings of "readiness." He proposes a "vision of a meeting place" within which values, ethics, understandings, and practices are shared between education sectors. I would argue that such a space would provide the opportunity for the emergence of reconceptualized understandings of "readiness" such as the concept of "becoming-ready" discussed in this paper. It would be pessimistic to suggest that there are currently no such spaces for the emergence of complexity and non-hierarchical understandings of "readiness," however in my experience, these spaces are often small and in the face of dominant policy-based discourses, voices and experiences from within these spaces can become lost and marginalized, consigned to the fringes of the mainstream, or silenced completely.

In concluding this article I argue that one vital step towards opening spaces for alternative understandings of "readiness" is to actively seek instances of resistance to dominant discourses and to find spaces within the educational landscape where such alternative understandings and narratives of struggle and resistance against dominant discourses can be heard. Stories of resistance must be celebrated openly, exposing the 
challenges and struggles of those who choose to think and act critically in response to the status quo. In response to dominant discourses of "readiness" within early childhood education in England, I would argue that there is a need for further radical critique of the conceptualization and representation of "readiness," building on the work of critical thinkers such as Ball and Moss in order to develop alternative understandings of "readiness" in practice, such as the notion of "becoming-ready" developed in this paper. Such radical critique is undoubtedly difficult. However, I believe that it is important, perhaps now more so than ever in the light of continued moves towards normativity, performativity, and the reduction of complexity in early childhood education. It is incumbent upon those of us working in the field, whether as practitioners or researchers, to ask difficult questions of ourselves, our practice, and the kind of education system we want to create for our children. We must draw on the encouragement of critics such as Moss to take a critical path, to summon the courage to put "our heads above the parapet" in the critique of the status quo, and hopefully, in the process, open up space for additional complexity in our understandings of "readiness" and of early childhood education more generally.

\section{References}

Allen, G. (2011). Early Intervention: The Next Steps. An Independent Report to Her Majesty's Government. Retrieved from http://www. dwp.gov.uk/docs/early-intervention-nextsteps.pdf

Ball, S. (2003). The teacher's soul and the terrors of performativity. Journal of Education Policy, 18(2), 215-228.

Biesta, G. J. J. (2010). Five Theses on Complexity Reduction and its Politics. In Osberg, D. \& Biesta, G. (Eds.), Complexity Theory and the Politics of Education (pp. 5-13). Rotterdam: Sense Publishers.

Brown, C. P. (2010). Balancing the readiness equation on early childhood education reform. Journal of Early Childhood Research, 8(2), 133-160.

Cole, D, R. (2011). The actions of affect in Deleuze: Others using language and the language that we make. Educational Philosophy and Theory, 43(6), 549-561.
Deleuze, G., \& Guattari, F. (1987). A thousand plateaus: Capitalism and schizophrenia. Trans. Massumi, B., London: Althone.

Department for Education (DfE). (2012). Statutory Framework for the Early Years Foundation Stage. Retrieved from https://www.educa tion.gov.uk/publications/standard/AllPub lications/Page1/DFE-00023-2012

Department for Education (DfE). (2013). Early Years Outcomes. A non-statutory guide for practitioners and inspectors to help inform understanding of child development through the early years. Retrieved from https://www. gov.uk/government/publications

Early Education. (2012). Development Matters in the Early Years Foundation Stage (EYFS). Retrieved from http://www.foundationyears.org.uk/wp -content/uploads/2012/03/DevelopmentMatters-FINAL-PRINT-AMENDED.pdf 
Field, F. (2010). The Foundation Years: preventing poor children becoming poor adults. The report of the Independent Review on Poverty and Life Chances. Retrieved from http://webarchive. nationalarchives.gov.uk/20110120090128/ http:/povertyreview.independent.gov.uk/ media/20254/poverty-report.pdf

Gove, M. (2011, September). Speech to the Durand Academy. Speech presented at the Durand Academy, Stockwell, London. Retrieved from http://www.michaelgove.com/news/ michael-goves-speech-durand-academy

Gustafson, R. I. (2010). Assuming Equal Intelligence in School Music and Language Study. In Osberg, D. \& Biesta, G. (Eds.) Complexity Theory and the Politics of Education (pp. 93-106). Rotterdam: Sense Publishers.

Jackson, A. Y. (2013). Data-as-Machine: A Deleuzian Becoming. In Coleman, R. and Ringrose, J. (Eds), Deleuze and Research Methodologies (pp. 111-124). Edinburgh: Edinburgh University Press Ltd.

Kagan, S. L. (2007). Readiness - multiple meanings and perspectives. In Woodhead, M. \& Moss, P. (Eds.), Early Childhood and Primary Education: Transitions in the Lives of Young Children. The Open University. Retrieved from http://www.bernardvanleer.org/Early_Child hood_and_Primary_Education_Transitions_ in_the_Lives_of_Young_Children.

Lenz Taguchi, H. (2010). Rethinking pedagogical practices in early childhood education: a multidimensional approach to learning and inclusion. In Yelland, N. (Ed.) (2010), Contemporary Perspectives on Early Childhood Education (pp. 14-32). Maidenhead: Open University Press.

Marble, S. (2012). Becoming-teacher: Encounters with the Other in teacher education. Discourse: Studies in the Cultural Politics of Education, 33(1), 21-31.

Meisels, S. J. (1999). Assessing Readiness. In Pianta, R. C. \& Cox, M. J. (Eds.), The Transition from Kindergarten. A series from the National Centre for Early Development and Learning (pp. 39-66). York: Paul H. Brookes Publishing.
Moss, P. (2012). Readiness, Partnership, a Meeting Place? Some Thoughts on the Possible Relationship between Early Childhood and Compulsory School Education. FORUM, 54(3), 355-368.

Moss, P. (2013). The relationship between early childhood and compulsory education: A properly political question. In Moss, P. (ed.), Early Childhood and Compulsory Education: Reconceptualising the relationship (pp. 2-49). Oxon: Routledge.

OECD (Organisation for Economic Co-operation and Development). (2001). Starting Strong I: Early Childhood Education and Care. Paris: OECD.

OECD (Organisation for Economic Co-operation and Development). (2006). Starting Strong II: Early Childhood Education and Care. Paris: OECD.

OECD (Organisation for Economic Co-operation and Development). (2012). Starting Strong III: A Quality Toolbox for Early Childhood Education and Care. Paris: OECD.

Olsson, L. M. (2009). Movement and experimentation in young children's learning, Deleuze and Guattari in early childhood education. Oxon: Routledge.

Sellers, M. (2013). Young children becoming curriculum. Deleuze, Te Whariki and curricular understandings. Oxon: Routledge.

Simons, M., \& Olssen, M. (2010). The School and Learning Apparatus. In Osberg, D. \& Biesta, G. (Eds.), Complexity Theory and the Politics of Education (pp. 79-91). Rotterdam: Sense Publishers.

Stagoll, C. (2005a). Becoming. In Parr, A. (Ed), The Deleuze Dictionary. Edinburgh: Edinburgh University Press.

Stagoll, C. (2005b). Arborescent Schema. In Parr, A. (Ed), The Deleuze Dictionary. Edinburgh: Edinburgh University Press.

Standards and Testing Agency (STA). (2013). Early Years Foundation Stage Profile Handbook. Retrieved from https://www.education.gov. uk/eyfsp. 
Tickell, C. (2011). The Early Years: Foundations for life, health and learning. An independent Report on the Early Tears Foundation Stage to Her Majesty's Government. Retrieved from http://media.education.gov.uk/MediaFiles/ B/1/5/\%7BB15EFF0D-A4DF-4294-93A11E1B88C13F68\%7DTickell\%20review.pdf.
Whitebread, D., \& Bingham, S. (2011). School Readiness: a critical review of perspectives and evidence. TACTYC. Retrieved from http:// www.tactyc.org.uk/occasional-papers/ occasional-paper2.pdf

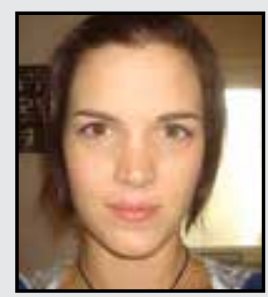

Katherine Evans is currently a $\mathrm{PhD}$ candidate in the Graduate School of Education, University of Exeter. The focus of her research is the disruption and reconceptualization of discourses of "readiness" within early childhood education in England. Prior to beginning her doctoral research she worked for many years as an early childhood teacher within schools and children's centres across the United Kingdom. She is particularly interested in the potential of critical and post-structural thinking to affect the development of more equitable and inclusive education practices and to disrupt taken-for-granted discourses within the early childhood field. 